\title{
Yeba Dance Exercise: It's Impact on the Physical Fitness among Overweight Students of Naawan, Misamis Oriental, Philippines
}

\author{
Rosevel B. Colegado \\ Assistant Professor IV \\ College of Education and Social Sciences \\ Mindanao State University at Naawan \\ Philippines \\ Dr. Rebecca M. Alquizar \\ College of Education \\ Mindanao State University-Iligan Institite of Technology \\ Philippines
}

\begin{abstract}
Yeba is a dance exercise which is a combination of the basic dance steps in folk, tribal, pop, hip-hop, and social dances put into a dance routine. This study was conducted to examine the association between YEBA dance exercise and fitness status among overweight students of Naawan, Misamis Oriental. A quasi-experimental design was used to find out the significant difference of the pre and post health related physical fitness tests. A standard health-related physical fitness test with its corresponding score scale was used to measure the evaluation of their performance. Results showed that participating in Yeba Dance Exercise improved the muscular endurance of the girls, lower back flexibility and Body Mass Index for both boys and girls. Likewise, the study emphasizes the importance and success for overweight students that improved their physical fitness, and health benefits are concomitant. Furthermore, improved endurance and lower back flexibility was observed during different fitness tests conducted for both boys and girls. In conclusion, this study indicates that overweight and obese students can improve their muscular endurance and flexibility with interventions consisting of a variety of physical activity programs.
\end{abstract}

Keywords: Yeba Dance Exercise, Physical Fitness, Overweight Students

\subsection{Introduction}

Living a healthy and happy life must start in the earlier stage of the adolescents' life. Their health habits and practices today as well as in the past, will greatly affect the status of their future health. Contrary to this phenomenon, it has been observed today that overweight among teenagers has played a very serious problem to all Filipinos and even worldwide. The WHO further projects that by 2015, approximately 2-3 billion adults will be overweight and more than 700 million will be obese. Furthermore, in the Philippines, overweight children below five years old have become rampant, listing a 400\% percent increase from 1\% in 1992 to 5 percent in 2013 (Perez, A, CNN Phil. 2016). To address this problem, every individual should acquire physical fitness, through regular physical activities that will burn the caloric intake of their body. One of the best physical activities is through the newest dance exercises called Yeba. This is a full workout that involves the upper and the lower extremities of the body which burns up to 500 calories and is believed to be a very good venue for the teenagers as well as every individual to maintain a healthy lifestyle while promoting a sense of awareness of one's culture and traditions. In this connection, the researcher decided to investigate the impact of the newly introduced dance exercise Yeba on the health related physical fitness along with other moderating variables that may affect the health status among the high school overweight students of Naawan, Misamis Oriental.

This study is anchored on many theories and concepts that best expound as to how physical fitness variables affect the health status of the overweight students. Historians, sociologists, archeologists, and anthropologists who study human primitive ancestors and ancient civilizations have long noted the importance of physical activity and physical expression. It may manifest itself in play, dance, sports or a means of survival (Mechikoff R. A., 2014. )According to Robbins and others (2002), physical fitness refers to a fit individual who is able to complete the normal routine for the day and still have ample reserve energy to meet the other demands of daily life - recreational sports and other leisure activities, and energy to handle life's emergency situations. 
It is also a set of attributes that people have that relates to the ability to perform physical activity (USDHHS, 1996). It is believed that physical activity refers to a bodily movement produced by skeletal muscles that require energy expenditure and produce progressive health benefits (Hoegen \& Hoegen, 2005). Regardless of the new study published in the Journal Medicine \& Science in Sports \& Exercise suggests that, contrary to what many people believe, mundane activities such as walking around the office and climbing stairs have a positive impact on health. However, in the book conceptualized by Hoeger and Hoeger (2013) they added that physical activity that is done regularly is said to produce health benefits and thus is considered to be a form of exercise.

Regular exercise can help mitigate the debilitating effect of old age. To be most effective in mitigating the effect of aging, the integration of regular physical activity into one's lifestyle should begin early in life (Wuest and other, 2009). Furthermore, an increased physical Activity and adoption of healthy eating habits would increase fitness and reduce body mass index among adolescents (Flores, 1995).

\subsection{Methodology}

This study used the quasi-experimental research design to determine the significant difference of the pre and post health related physical fitness among the 23 overweight high school students of Naawan Misamis Oriental. A standardized health related physical fitness test with corresponding score scale for the evaluation of their performance. A self-made questionnaire was designed consisting of two parts. Part one was on the nature and extent of physical activities of each child. Part two consisted of questions and choices reflecting the acting patterns and food preferences of each participant.

The study was conducted at Naawan Misamis Oriental Region 10 covering two secondary schools during the second semester of calendar year 2015-2016. There were 102 qualified respondents, only 58 signified to join the program but because of some reasonable circumstances, only 23 overweight high school students continued to join the Yeba dance exercise program for 3 months, 3 days a week at one and 30 minutes per session

\subsection{Statistical Treatment of Data}

Mean was used to find the average score of the pre-post health-related physical fitness test components such as cardiovascular endurance, muscular strength, muscular endurance, flexibility, and BMI.

Percentage was used to describe the respondents' profile in terms of age, sex, other physical activities, food intake, and BMI and the profile of the respondents' pre-post health-related physical fitness components (cardiovascular endurance, muscular strength and endurance, flexibility, BMI)

Chi square statistic was used to show the relationship between the pre-post health-related physical fitness components (cardiovascular endurance, muscular strength and endurance, flexibility, BMI) and Yeba dance exercise (FITT) with the moderating variables (age, sex, socio economic status, other physical activities, food intake, and BMI) Paired TTest was used to find the significant difference of the pre-post health-related physical fitness components such as cardio vascular endurance, muscular strength and endurance, flexibility, and BMI.

\subsection{Results and Discussion}

Figure 16 result shows the percentage distribution of the respondents' pre and post-test on muscular strength $(90$ degrees push-up for male and modified push-up for female). Thirty-nine percent (39\%) of the respondents were in low zone during the pre-test and dropped to $17 \%$ in the post test. Thirty-five percent $(35 \%)$ were in the high performance zone during the pre-test and rose to $52 \%$ in the post-test. In the marginal zone, both the pre and post-test attained $17 \%$, $9 \%$ is in the good fitness zone during the pre-test and rose $13 \%$ in the post-test. This implies that a good percentage of the respondents attained a high performance level during the posttest which means that the program developed their muscular strength which is very necessary for adolescents in performing their activities in school and at their respective households. However, the mean was -3.35 with a p-value of 0.0875 which did not show a significant relationship.

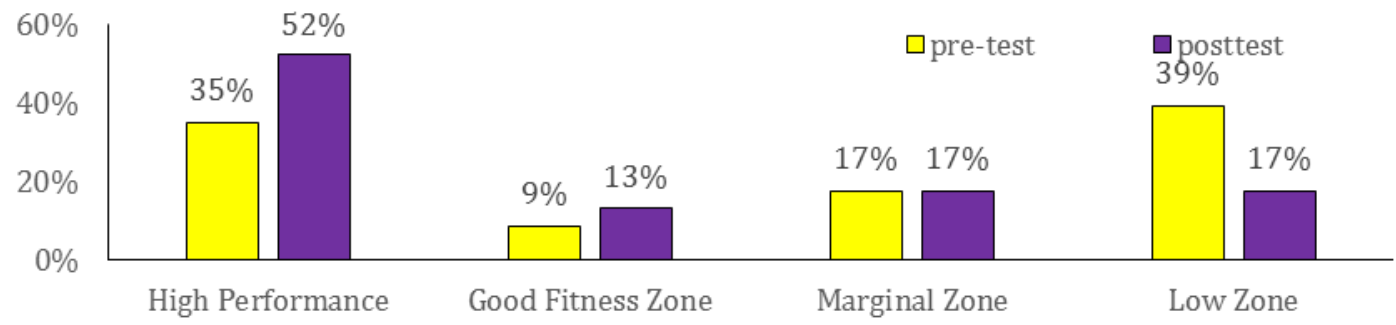

Figure16. Percentage Distribution of the Respondents' Pre-Post Test on Muscular Strength (90 degrees push-up for Male and modified push-up for female) 
Figure 17 shows the percentage distribution of the respondents' pre and post-test on muscular endurance (abdominal curl-up). Sixty-one percent (61\%) of the respondents were in the low zone during the pre-test and $13 \%$ in the post test, $22 \%$ were in the marginal zone during the pre-test and rose to $61 \%$ in the post-test while $17 \%$ were in the good fitness zone during the pre-test and $22 \%$ in the post-test, $0 \%$ in the high performance zone during the pre-test and $4 \%$ in the post test. This reveals that there is a high difference in the marginal zone from the pretest to the post test. It appears that there is a transfer of performance from the low performance zone to the marginal zone. This incidence is a good result for overweight if they continue the exercise at the same phase but in a longer period of time. It is best attained if it is done regularly and with a commitment to lose weight.

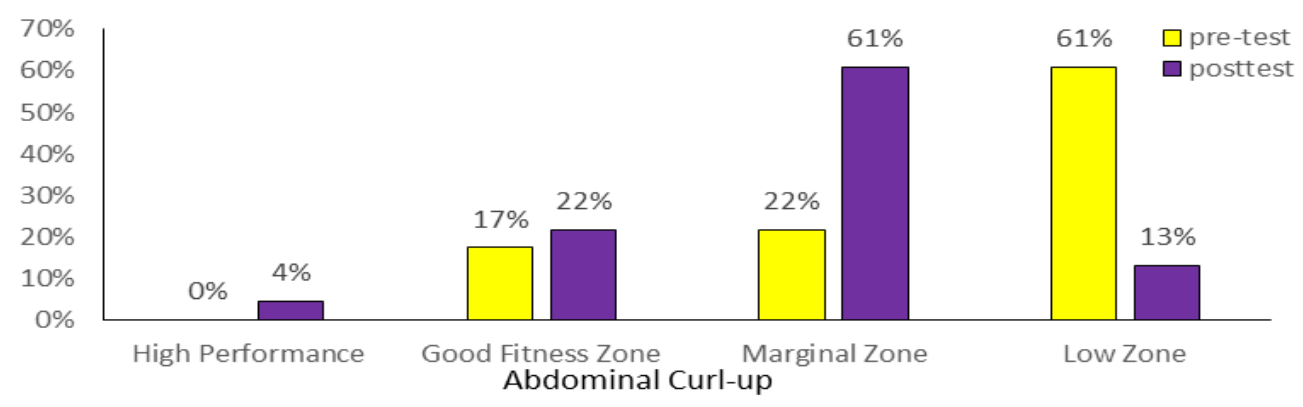

Figure17. Percentage Distribution of the Respondents' Pre-Post Test Result on Muscular Endurance

Figure 18 presents the percentage distribution of the respondents' pre and post-test result on flexibility (modified sit and reach). Forty-three percent (43\%) of the respondents showed an excellent flexibility during the pre-test and rose to $61 \%$ in the post-test, $17 \%$ were on poor status during the pre-test and went down to $4 \%$ in the post-test, $13 \%$ were in good status during the pre-test and $17 \%$ in the post test, while in the Fair status, both attained 13\% during the pre and post-test, and $13 \%$ are in average status during the pre and $4 \%$ in the post test. This implies that the result was consistently excellent from the pretest to posttest and showed that the exercise program improved the respondents' range of motion which is necessary for doing the tasks as students.

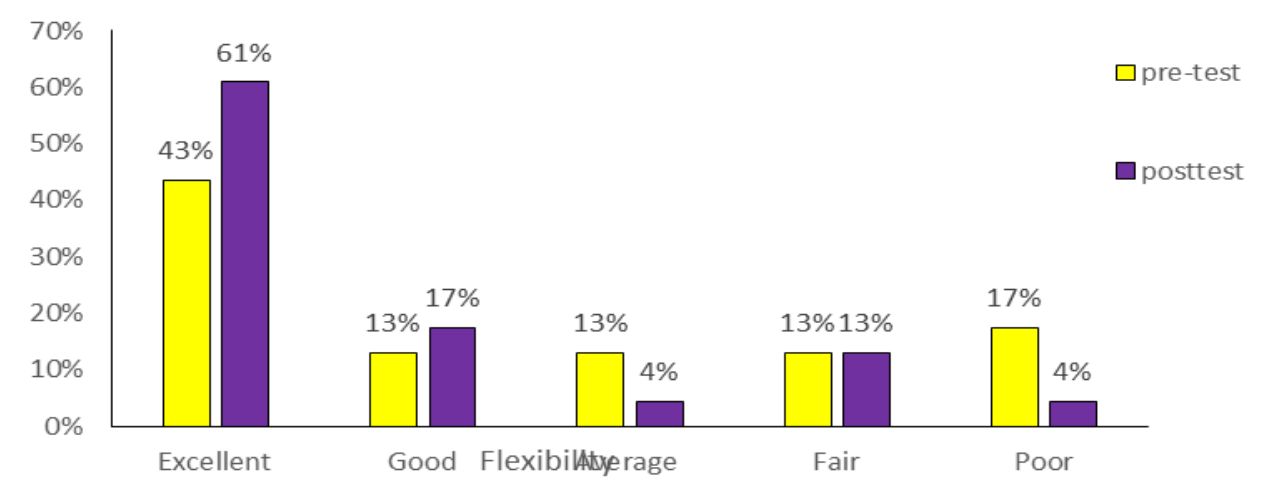

Figure18. Percentage Distribution of the Respondents' Pre-Post Test Results on Flexibility (Modified sit and reach)

Figure 19 presents the percentage distribution of the respondents' pre and post-test results on body composition (BMI). Sixty-one percent $(61 \%)$ of the respondents were in the overweight category during the pre-test and went down to $30 \%$ in the post test which denotes a reduction in the body mass composition to almost half of the respondents. Thirty-nine (39\%) of the respondents classified as obese during the pre-test went down to $9 \%$ in the post test which signifies a reduced percentage of most of the respondents. In the normal composition $61 \%$ of the respondents were normal in the post test. This means that there a transfer of result from the overweight pre-test to normal health status in the post test. This result satisfies the aim of physical fitness through physical activity such as Yeba dance exercise which is done on regular basis especially for obese and overweight individuals. 


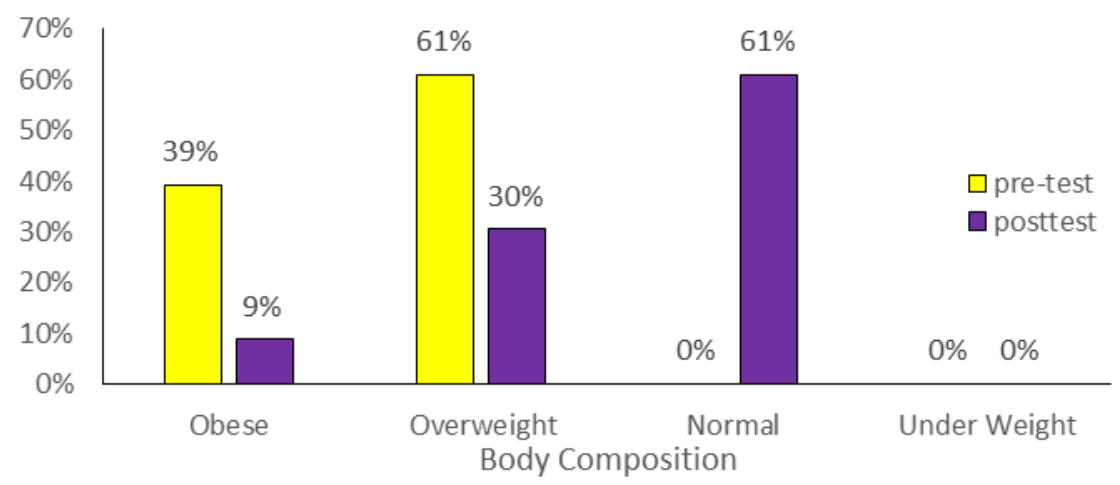

Figure 19. Percentage Distribution of the Respondents' Pre-Post Test Results on Body Composition (BMI)

Table 8. Paired t-test result on the relationship between the pre and post health related physical fitness test.

\begin{tabular}{|l|l|l|l|l|l|} 
Physical Fitness Test & $\begin{array}{l}\text { Mean } \\
\text { (Pre-Post) } \\
\text { Test }\end{array}$ & M.D. & t-value & p-value & Remarks \\
\hline The Step test & $119.04-111.44$ & 7.61 & 1.76 & 0.0923 & Not significant \\
\hline Push-Up & $17.0-20.35$ & -3.35 & -1.79 & 0.0875 & Not significant \\
\hline Curl-Up & $12.0-17.57$ & -5.57 & -4.69 & $\mathbf{0 . 0 0 0 1} *$ & Significant \\
Sit and Reach & $39.33-45.54$ & -6.22 & -3.69 & $\mathbf{0 . 0 0 1 3} *$ & Significant \\
BMI & $29.63-27.29$ & 2.34 & 3.67 & $\mathbf{0 . 0 0 1 4} *$ & Significant \\
\hline
\end{tabular}

*Significant when P-value is less than 0.05 - $95 \%$ level of confidence

**Significant when P-value is less than 0.01 - $99 \%$ level of confidence

*** Significance when $\mathbf{P}$-value is less than $0.001-99.9 \%$ level of confidence

Therefore, this study shows a significant difference between the pre-test and post-test health related physical fitness on the health status of the overweight students of Naawan, Misamis Oriental. Several respondents who were religiously attending the program were found to have achieved a greater effect on all the components tested. However, those who were inconsistent in joining the program were found to have less effect. Regular engagement of Yeba dance exercise created a significant difference on the health status of the respondents as reflected on the pre-post test result of the study. Somehow if the respondents were committed and determined to return to their normal health status, a great effect on all the components would have been observed.

\subsection{Conclusion and Recommendations}

\subsection{Conclusion}

The incidence of overweight and obesity among high school students in Naawan, Misamis Oriental remains low and are in the age bracket 14-15 and are highest among female with family income of 21,000 to 25,000 belonging to the lower middle income status (NSO, 2015). The major cause of overweight is decreased light physical activity. Most of the overweight or obese students have light physical activity with some inactive activities such as watching television, doing assignments, and playing video games. There is a lack of physical activity in school and even at home. The convenience of advanced technology causes the students' health at risk by creating a sedentary lifestyle among adolescents. Sport activities in school were not a priority to the respondents especially among females. The freedom of making their own choices of food also plays a significant factor in the development of overweight and obesity. Although, it is our choice to make our children physically active and train them to become independent in the different aspect of their personality but we should not neglect the fact that a healthy mind needs a healthy body, thus being physically fit is an essential and not a choice anymore.

It is concluded that an engagement in physical activity such as Yeba dance exercise improves the muscular endurance of the girls' lower back flexibility and Body Mass Index for both boys and girls were also improved. It also emphasizes the importance and success of this exercise to overweight students to improve physical fitness and that 
some, but not all, health benefits may be associated. Above all, the success of this study depends on the commitment of the subject to change their lifestyle and develop healthy habits to live a good life.

\subsection{Recommendations}

Based on the findings and conclusion of this study, the following recommendations are forwarded

1. Parents should encourage their children to engage in any wellness program such as Yeba dance exercise in school as well as allowing them to join other regular physical activities in the community. Furthermore, they should encourage their children to perform household chores regularly. (See Table 8, page)

2. For administrators, they should design a curriculum to incorporate in their P.E classes the aerobic exercises and other recreational activities daily and providing them enough facilities for the implementation of this program.

4. For future researches, this study may be used to test the cultural awareness of the students.

5. Furthermore, this study can be useful on researches concerning muscles on which part (upper and lower extremities) have improved more.

6. It is recommended that a graduate student writes a module to be integrated in the MAPEH Curriculum.

7. Should this study be replicated, a bigger sample should be used.

Table 8. Suggested Physical Activities for a Week

PHYSICAL ACTIVITIES FOR A WEEK

\begin{tabular}{l|l|l} 
Cut Down On & $\mathbf{2 - 3}$ times a week & 3-5 Times a week \\
Watching T.V. & Leisure and & Aerobic Exercises \\
Video and Computer Game & Playtime & Roller Blading \\
Sitting more than 30 minutes & Swinging & Biking \\
at a time & Boating & Skate boarding \\
& Tumbling & Rope Climbing \\
& Miniature & Swimming \\
& Golf & Running \\
& Strength and & Recreational \\
& Flexibility & Activities \\
& Push-up/pull-up & Volleyball \\
& Basketball \\
& Dartial Art & Soccer \\
& Dancing (YEBA) & Skiing \\
& Rope Climbing & Kickball \\
& Relay Races \\
\hline
\end{tabular}

Everyday

As often as possible

Play outside

Take the stairs

instead of the

elevator

Health around the house

or yard

Bathe your pets

Pick up your toys

Walk to the store

Go for a walk

Table 8 shows the suggested physical activities for a week. The activities that will be cut down are watching TV, video and computer games, and sitting more than 30 minutes at a time. These activities are considered sedentary (inactive) that can have negative impact on one' health. Children who are physically inactive are more prone to health problems like obesity or other health-related difficulties. (Cited in the study of Obesity School-Aged Children: Prevalence and Causes).

Suggested physical activities that should be done two to three times a week are divided into leisure and playtime (swinging, boating, tumbling miniature, and golf) and Strength and flexibility (push-up and pull-up, martial arts, Yeba dance exercise, and rope climbing). These will help overweight students to lose weight and enjoy the benefits of having tone up bodies. For those who are in normal status, it will help them maintain their desired weight while enjoying the opportunity to become free from diseases and have extra reserve energy in times of emergency. As recommended by Hippocrates, a person engaging physical activity with moderate intensity can enjoy a healthy body and well-being. For three to five times a week activities, this may include the aerobic exercises (roller blading, biking, skate boarding, rope climbing, swimming, and running) and recreational activities (volleyball, basketball, soccer, skiing, kickball, relay Races). These physical activities are slightly strenuous but it is very helpful in maintaining a normal status and preventing an individual from acquiring disabilities. This acquired energy is very useful in the daily performance of a person's duties and responsibilities in their respective workplace, in school and in the community as a whole. For the daily activities, we should learn how to mingle with others by playing outside especially for adolescents'; have the chance of taking the stairs instead of the elevator. Health or cleaning around the house or yard is a must to become healthy. Taking care of animals or pets like bathing them, are necessary to maintain cleanliness at home. A habit of keeping and picking up of toys and other things used in recreation for children and adults should be practiced. Walking also plays a significant role in maintaining health status and preventing any diseases. Although, we are not always free 
from diseases but it is still advantageous if we are physically fit and this can be attained through regular physical activities.

\section{List of References}

Hoeger, W. and Hoeger S. (2005). Lifetime physical fitness and wellness: A personalized program ( $8^{\text {th }}$ ed.). Thomson and Wadswort, Cengage Learning, USA.

Hoeger, W. and Hoeger S. (2013). Lifetime physical fitness and wellness: A personalized program (12 ${ }^{\text {th }}$ ed.). Thomson and Wadswort, Cengage Learning, USA.

Lopez, L.F.P.,Beldia, McD, D.,Pangan R. J. (2000). Physical Education, Health, and Music I. , 856 Nicanor Reyes, Sr. St., C.M. Recto Avenue, Manila, Philippines, Rex Store Store.

Mechikoff, R.A. (2014). A History and Philosophy of Sports and Physical Education from Ancient Civilization to Modern World. McGraw-Hill Campanies Inc. 1221, Avenue of the Americans, NY 10020.

Robins,G., D. Powers, \& S. Burgess. 2002. A wellness way of life. New York: McGraw-Hill Co.

U.S. Department of Health \& Human Services. 1996. Physical activity and health: A report of the Surgeon General. Atlanta, GA: U.S. Department of Health and Human Services, Centers for Disease Control and Prevention, National Center for Chronic Disease Prevention and Health Promotion.

Philippine Star.com. (2014). Anti-Obesity Program (HB 4314). http://www.builtlean.com/2012/02/02/physical-fitness.

http:/www. Mindmapart.com/health-mind-map-jane-genovese. "The Health Mind Map". 2011. www.Rcmp.gc.ca./2012.03.09. www.sonv.org/intro/pdfs/traning_principle.pdf www.wikipedia.com file:///C:/Users/RVC/Downloads/Desktop/yeba/the-importance-of-health-fitness-and-wellness.htm file:///E:/\%C2\%A0/yeba/the-importance-of-health-fitness-and-wellness.htm. 